\title{
Resveratrol-Loaded Lipid Nanocarriers Are Internalized By Endocytosis In Yeast
}

Célia Barbosa ${ }^{\dagger}, \#$, Cátia Santos-Pereira ${ }^{\dagger, \ddagger, \#}$, Inês Soares ${ }^{\dagger}$, , Viviana Martins ${ }^{\dagger, \S}$, Joana Terra-Matos ${ }^{\dagger}$, Manuela Côrte-Real ${ }^{\dagger}$, Marlene Lúcio ${ }^{\perp *}$, M. E. C. D. Real Oliveira ${ }^{\perp}$, Hernâni Gerós ${ }^{\dagger, \ddagger}, \S *$

${ }^{\dagger}$ Centre of Molecular and Environmental Biology (CBMA), Department of Biology, University of Minho, Campus of Gualtar, 4710-057 Braga, Portugal

Centre of Biological Engineering (CEB), Department of Biological Engineering, University of Minho, Campus de Gualtar, 4710-057, Braga, Portugal

${ }^{\S}$ Centre for the Research and Technology of Agro-Environmental and Biological Sciences (CITAB), University of Trás-os-Montes e Alto Douro, Quinta de Prados, 5000-801 Vila Real, Portugal

${ }^{\perp}$ Centre of Physics (CFUM), Department of Physics, University of Minho, Campus of Gualtar, 4710-057 Braga, Portugal 
A

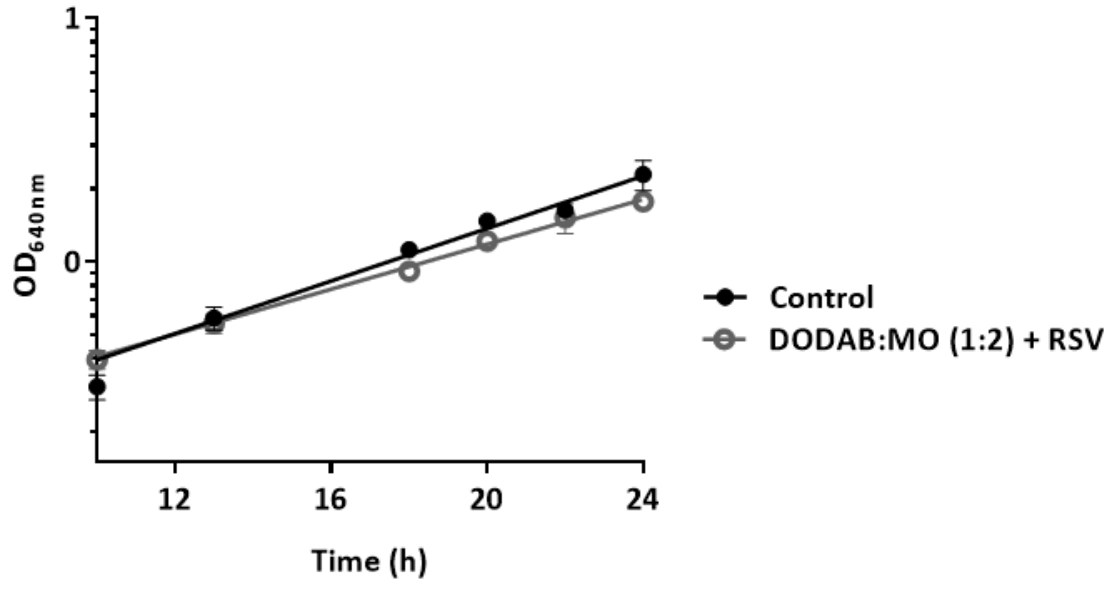

B
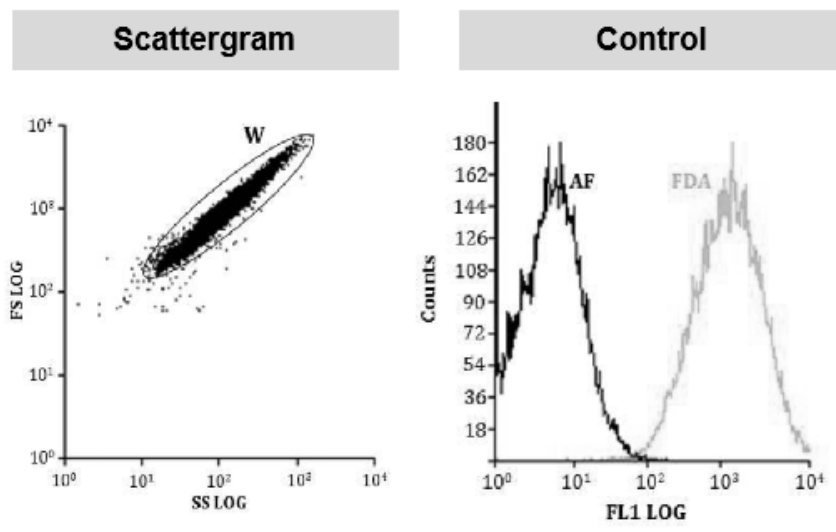

\section{DODAB:MO (1:2) + $200 \mu M$ RSV}

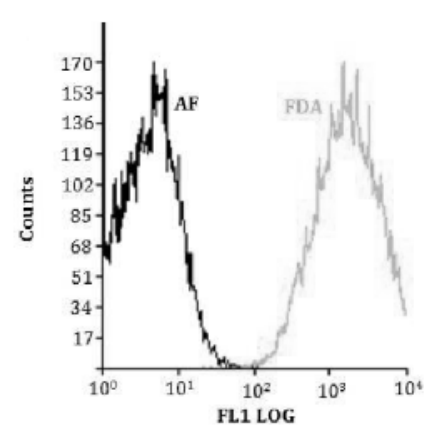

Supplementary figure 1. The internalization of RSV-loaded nanocarriers does not affect yeast cell growth or viability. (A) S. cerevisiae W303-1A cells were incubated up to $24 \mathrm{~h}$ in the absence or presence of DODAB:MO (1:2) nanocarriers loaded with $200 \mu \mathrm{M}$ RSV. The plot represents the exponential growth curves of both conditions from 10-24 h incubation. (B) Cells were incubated for $30 \mathrm{~min}$ in the absence or presence of DODAB:MO (1:2) nanocarriers loaded with $200 \mu \mathrm{M}$ RSV and cell viability was assessed by flow cytometry with the FDA probe. The scattergram of the population of yeast cells in the absence of RSV (left panel), and overlay histograms of autofluorescence (black line) and FDA stained cells (grey line) in the absence (control) or presence of RSV-loaded nanocarriers are shown. 